\title{
Spring mortality of the cyclopoid copepod Oithona similis in polar waters
}

\author{
A. G. Hirst ${ }^{1,2, *}$, P. Ward ${ }^{1}$ \\ ${ }^{1}$ British Antarctic Survey (BAS), Natural Environment Research Council, High Cross, Madingley Road, Cambridge, CB3 0ET, UK \\ ${ }^{2}$ Present address: School of Biological and Chemical Sciences, Queen Mary, University of London, Mile End Road, \\ London E1 4NS, UK
}

\begin{abstract}
The cyclopoid copepod Oithona similis is highly abundant and ubiquitous in the marine epipelagic environment, yet rates of mortality in this species have rarely been quantified; indeed we are lacking such measurements for Copepoda in general in cold waters. In the present study we examined $O$. similis stage structure, egg production and mortality rates across the Scotia Sea, Southern Ocean, sampling from the ice edge to the Polar Front in the austral spring of 2006. The population stage structure near the retreating ice edge was indicative of a recruitment pulse moving through the younger stages; therefore, the assumptions of the vertical life table (VLT) approach were not met and mortality was not estimated for those stations. At all other stations the assumptions of VLT were largely met, and mortality rates were determined as across-station averages. The highest rates of mortality occurred across the egg to NII stages at around $0.04 \mathrm{~d}^{-1}$, falling to $<0.03 \mathrm{~d}^{-1}$ in subsequent stages, and then increasing again to $0.11 \mathrm{~d}^{-1}$ across copepod stage $\mathrm{V}$ to adult males. The ratio of adult males to females suggested that males have a mortality rate 12 times greater than females (i.e. the adult male to female abundance ratio is 0.08 ). It is unlikely that these differences can be attributed simply to the males' shorter physiological longevity (longevity when free of predators); the primary cause is likely elevated predation mortality due to the risks associated with mate locating behaviour.
\end{abstract}

KEY WORDS: Oithona similis · Mortality $\cdot$ Stage structure $\cdot$ Egg production · Vertical life table Scotia Sea

Resale or republication not permitted without written consent of the publisher

\section{INTRODUCTION}

Oithona similis is a marine, pelagic, cyclopoid copepod distributed from the subtropics to polar waters. It is extremely abundant in many planktonic systems, and has been described as one of the most important copepod species based on its numerical dominance (Gallienne \& Robins 2001). The genus Oithona has relatively low daily egg production rates (EPR) in comparison to many broadcast spawning species (Bunker \& Hirst 2004); however, pelagic copepods that carry their eggs typically have much lower rates of egg mortality than those that freely spawn eggs (Kiørboe 1998, Hirst \& Kiørboe 2002). Recently, EPR by Oithona similis have been described in Antarctic (Scotia Sea) waters during 2 consecutive summers (Ward \& Hirst 2007) and were found to be temperature dependent and well below maximum food saturated levels. In colder waters, egg hatch times are much extended compared to warmer waters; therefore, the time between the laying of 2 consecutive clutches (interclutch period) is greater and the achieved daily EPR are lower. Relatively low EPR and long egg to adult development times both imply relatively low average mortality rates of copepods in polar environments (Hirst \& Kiørboe 2002, Ward \& Hirst 2007).

Although considerable effort has been expended on EPR and growth rate studies of marine copepods over the last few decades (Hirst \& Bunker 2003, Bunker \& Hirst 2004), these alone are insufficient to understand the dynamics and seasonality of populations, as the loss terms, including mortality, are also critical to these dynamics. Only 2 studies have examined natural rates of mortality in Oithona (i.e. Eiane \& Ohman 2004, Thor 
et al. 2008). Furthermore, there are only a few estimates of copepod mortality in high latitudes (e.g. Matthews et al. 1978, Ohman \& Hirche 2001, Heath et al. 2008), and epi-pelagic values from polar waters are especially sparse (e.g. Thor et al. 2008). This may be due, in part, to the fact that assumptions associated with a vertical life table (VLT) approach (continuous recruitment, approximately steadystate population structure) can be more difficult to meet in these highly seasonal systems that are often dominated by strong cohort recruitment patterns. Horizontal methods are also difficult to apply in open ocean and advective environments because of the need for continued samples from the same population over time. In the present study we examined the stage structure, egg production and mortality rates of the copepod $O$. similis across the Scotia Sea from the ice edge to the Antarctic Polar Front (APF) in the austral spring (October to November) of 2006 using a VLT approach.

\section{MATERIALS AND METHODS}

Sample collection. Samples were collected aboard RRS 'James Clark Ross' in late October to early December 2006, along a transect across the Scotia Sea, from near the edge of the seasonal ice extent, which was in retreat at that time of the year, up to the APF. The locations of all stations and the extent of seasonal ice during November are given in Fig. 1, and times and dates of all collections are given in Table 1.

Estimating mortality in the Oithona similis population requires accurate estimates of the relative abundance for eggs, larval instars and adults. Accordingly, we used 3 methods to collect zooplankton samples and carried out a comparison amongst these approaches in order to assess sampling problems. At all stations, paired $50 \mu \mathrm{m}$ mesh bongo nets (each $2.3 \mathrm{~m}$ long with mouth diameter of $18 \mathrm{~cm}$ ) fitted with a filtering window in the hard plastic cod end (Sea-Gear) were used, as were motion compensated bongo nets (Shreeve 2002) with $100 \mu \mathrm{m}$ mesh nets $(2.8 \mathrm{~m}$ long with mouth diameter of $62 \mathrm{~cm}$ ). The motion compensator was attached between the tow wire and the net and, in effect, is a coiled spring which acts to remove the roll and pitch of the ship from the net motion. Both nets were fitted into bongo frames and hauled vertically via a single wire attached to a centre-fixing between the 2 nets from $400 \mathrm{~m}$ to the surface at a speed of $\sim 0.22 \mathrm{~m} \mathrm{~s}^{-1}$. We assumed the nets filtered with $100 \%$ efficiency so that
Table 1. Oithona similis. Dates and times of collection of samples using water bottles and 2 net types

\begin{tabular}{|c|c|c|c|}
\hline Stn & Collection method & Date (2006) & Time (GMT) \\
\hline \multirow[t]{6}{*}{ PS1 } & $100 \mu \mathrm{m}$ net & 27 Oct & $14: 50$ \\
\hline & $50 \mu \mathrm{m}$ net & 27 Oct & $17: 02$ \\
\hline & $50 \mu \mathrm{m}$ net & 27 Oct & $17: 37$ \\
\hline & Water bottle & 28 Oct & $12: 02$ \\
\hline & $100 \mu \mathrm{m}$ net & 29 Oct & $14: 58$ \\
\hline & $50 \mu \mathrm{m}$ net & 29 Oct & $21: 19$ \\
\hline \multirow{4}{*}{$\mathrm{CS} 1$} & $100 \mu \mathrm{m}$ net & $1 \mathrm{Nov}$ & $21: 00$ \\
\hline & Water bottle & $2 \mathrm{Nov}$ & 07:07 \\
\hline & $50 \mu \mathrm{m}$ net & $2 \mathrm{Nov}$ & $07: 44$ \\
\hline & $100 \mu \mathrm{m}$ net & $2 \mathrm{Nov}$ & 09:02 \\
\hline \multirow[t]{4}{*}{$\mathrm{CS} 2$} & $100 \mu \mathrm{m}$ net & $5 \mathrm{Nov}$ & $12: 34$ \\
\hline & Water bottle & $6 \mathrm{Nov}$ & 07:02 \\
\hline & $50 \mu \mathrm{m}$ net & $6 \mathrm{Nov}$ & 07:39 \\
\hline & $100 \mu \mathrm{m}$ net & $6 \mathrm{Nov}$ & $09: 24$ \\
\hline \multirow[t]{3}{*}{ CS3 } & Water bottle & $9 \mathrm{Nov}$ & 07:00 \\
\hline & $50 \mu \mathrm{m}$ net & $9 \mathrm{Nov}$ & $07: 35$ \\
\hline & $100 \mu \mathrm{m}$ net & $9 \mathrm{Nov}$ & $08: 29$ \\
\hline \multirow[t]{3}{*}{$\mathrm{CS} 4 / 5$} & $100 \mu \mathrm{m}$ net & $16 \mathrm{Nov}$ & 09:03 \\
\hline & Water bottle & $17 \mathrm{Nov}$ & $08: 45$ \\
\hline & $50 \mu \mathrm{m}$ net & $17 \mathrm{Nov}$ & 09:21 \\
\hline \multirow[t]{3}{*}{ PS2 } & $100 \mu \mathrm{m}$ net & $18 \mathrm{Nov}$ & $12: 30$ \\
\hline & $50 \mu \mathrm{m}$ net & $18 \mathrm{Nov}$ & $14: 38$ \\
\hline & Water bottle & $19 \mathrm{Nov}$ & $12: 24$ \\
\hline \multirow[t]{5}{*}{ PS3 } & $100 \mu \mathrm{m}$ net & $23 \mathrm{Nov}$ & $08: 13$ \\
\hline & $50 \mu \mathrm{m}$ net & $24 \mathrm{Nov}$ & $12: 38$ \\
\hline & Water bottle & $24 \mathrm{Nov}$ & $14: 34$ \\
\hline & $100 \mu \mathrm{m}$ net & $25 \mathrm{Nov}$ & $11: 24$ \\
\hline & $50 \mu \mathrm{m}$ net & $25 \mathrm{Nov}$ & $13: 43$ \\
\hline \multirow[t]{4}{*}{ CS6 } & $100 \mu \mathrm{m}$ net & $28 \mathrm{Nov}$ & $10: 00$ \\
\hline & Water bottle & $29 \mathrm{Nov}$ & 06:08 \\
\hline & $50 \mu \mathrm{m}$ net & $29 \mathrm{Nov}$ & $06: 42$ \\
\hline & $100 \mu \mathrm{m}$ net & $29 \mathrm{Nov}$ & $07: 40$ \\
\hline
\end{tabular}


the vertical tow from $400 \mathrm{~m}$ represented approximately 10 and $121 \mathrm{~m}^{3}$ of water filtered by the 50 and $100 \mu \mathrm{m}$ bongos, respectively. This assumption is examined in the 'Results' section.

Samples were preserved in $4 \%(\mathrm{w} / \mathrm{v})$ buffered formaldehyde. During sorting the samples were split into aliquots varying between $1 / 8$ and $1 / 512$ of the total. For each net 2 aliquots were counted and their results combined; total numbers were multiplied by the split fractions to obtain values for the total haul. Some stations were sampled with the $50 \mu \mathrm{m}$ nets twice or even 3 times over consecutive days; these replicates were sorted and are indicated in Table 1.

At all stations, collections were also made using an SBE 24 carousel water sampler, holding twelve $10 \mathrm{l}$ water bottles, connected to an SBE 9 plus CTD. Two water bottles (20 l) were collected just below the surface ( 0 m collection) and at 50,100, 200, 300 and $400 \mathrm{~m}$ depth. The contents of the 2 water bottles from each of the above depths were gently screened onto a $50 \mu \mathrm{m}$ mesh net and then backwashed into preserving jars, finally being preserved in buffered $4 \%(\mathrm{w} / \mathrm{v})$ formaldehyde. These samples were counted in their entirety for Oithona similis stages, and values were integrated over the depth between the depth of collection and the mid-depth between it and the nearest collections; for example, the density of individuals in the $50 \mathrm{~m}$ collection was assumed to apply over the 25 to $75 \mathrm{~m}$ depth range.

Staging and measuring. At each of the 8 stations 30 egg sacs (240 egg sacs in total) were dissected and the number of eggs per sac counted. For all 3 sampling methods (50 and $100 \mu \mathrm{m}$ nets, and water bottles) Oithona similis egg sacs were enumerated in the aliquots and converted to total egg numbers by multiplying by the overall mean across all stations (12.2 eggs $\left.\mathrm{sac}^{-1}\right)$. Two hundred nauplii from each sample were separated into stage pairs, specifically NI/NII, NIII/NIV and NV/NVI, according to the key of Sazhina (1985), and the proportions of each stage used to estimate their abundance. All copepodite stages in the subsamples (described above) were distinguished and counted; adults were also sexed and counted. Measurements of the length and width of each of stages NI-NII to CI (copepod stage I) $(\mathrm{n}=30)$ were made using an eyepiece micrometer at $\times 200$ magnification, and measured to the nearest $5 \mu \mathrm{m}$.

Stage duration. Accurate independent estimates of development times are necessary in order to determine mortality rates using VLT methods. We used the Bêlehràdek equation for development time $(D$, days):

$$
D=a(T+\alpha)^{-2.05}
$$

where $T$ is temperature $\left({ }^{\circ} \mathrm{C}\right)$ and with the $b$ parameter set at 2.05 .
To determine egg hatch times we applied the equation given by Nielsen et al. (2002), which is more suitable than other published values because it includes hatch times down to a temperature of $-1^{\circ} \mathrm{C}$. The lowest 0 to $100 \mathrm{~m}$ average water temperature in this study was $-0.93^{\circ} \mathrm{C}_{i}$ hence, we only apply the Nielsen et al. (2002) equation within its measured limits. For post-hatch stages we applied Eq. (1), with $\alpha$ as established for the eggs $(=7.6998)$. The $a$ values for post-hatch stages were determined using the stage-specific durations $(D)$ at $15^{\circ} \mathrm{C}$ as given by Sabatini \& Kiørboe $(1994$, their Fig. 7a) (M. Sabatini pers. comm.) by rearranging Eq. (1) and solving for $a$, as: $a=D / 0.00166$. Finally, these values were substituted to obtain stage durations as a function of temperature assuming equiproportional development. Parameters and sources of data are detailed in Table 2 . When predicting stage durations and mortalities we applied temperatures from the CTD averaged over 0 to $100 \mathrm{~m}$ of the water column, as at all stations the majority of the population was located in the upper $100 \mathrm{~m}$. Temperatures averaged over 0 to $400 \mathrm{~m}$, i.e. the full integration depth of the net tows, were always within $1.2^{\circ} \mathrm{C}$ of the 0 to $100 \mathrm{~m}$ temperature values, and usually differences were much less than this. EPR (eggs female $\mathrm{e}^{-1} \mathrm{~d}^{-1}$ ) of Oithona similis females were determined using the egg-ratio method (Edmondson et al. 1962, Checkley 1980) as:

$$
\mathrm{EPR}=\frac{E}{\left(F \times D_{\text {eggs }}\right)}
$$

where $E$ is the abundance (no. $\mathrm{m}^{-3}$ ) of eggs in the sample (the product of numbers of sacs and mean numbers of eggs per sac), $F$ the abundance of adult females (no. $\left.\mathrm{m}^{-3}\right)$, and $D_{\text {eggs }}$ the predicted egg hatch time (d).

Table 2. Values for a used to determine egg and post-hatch stage durations $\left(D\right.$, days) from temperature $\left(T,{ }^{\circ} \mathrm{C}\right)$ using the equation $D=a(T+7.6998)^{-2.05}$. The equation to describe egg development time from laying to hatching is from Nielsen et al. (2002); a parameters for the remaining stages are derived using data on stage-specific development times at $15^{\circ} \mathrm{C}$ (Sabatini \& Kiørboe 1994). For estimating NI+NII times we assumed that the times measured are from hatching (experiments were set up with a mix of egg bearing and non-bearing females)

\begin{tabular}{|lcl|}
\hline Stage & $a$ & \multicolumn{1}{c|}{ Source } \\
\hline Egg & 1504.5 & Nielsen et al. (2002) \\
NI+NII & 1606 & Sabatini \& Kiørboe (1994) \\
NIII & 1092 & Sabatini \& Kiørboe (1994) \\
NVI & 811 & Sabatini \& Kiørboe (1994) \\
NV & 878 & Sabatini \& Kiørboe (1994) \\
NIV & 1322 & Sabatini \& Kiørboe (1994) \\
CI & 761 & Sabatini \& Kiørboe (1994) \\
CII & 920 & Sabatini \& Kiørboe (1994) \\
CIII & 1121 & Sabatini \& Kiørboe (1994) \\
CIV & 987 & Sabatini \& Kiørboe (1994) \\
CV & 1129 & Sabatini \& Kiørboe (1994) \\
\hline
\end{tabular}


Mortality estimation. We used a VLT approach to solve for rates of mortality across each stage for each sampling event. A critical assumption behind VLT is that recruitment to a stage should not be characterized by an upward or downward trend (resulting for example from a cohort structure moving through the population) over the duration of the combination of stages over which mortality is being determined (Aksnes et al. 1997). There is evidence for the existence of such trends, i.e. a recruitment pulse in the stage structure, at the 3 most southerly stations (Stns CS1, CS2 and CS3), which were all very close to the retreating seasonal ice edge at the time of sampling. Although this situation is less marked at Stn CS3, there is nonetheless no steady decline in duration-corrected abundance across the naupliar stages. As such, these stations have not been included in any of the mortality estimates. Across the other stations (Stns CS4/5, CS6, PS1, PS2, PS3) there was no evidence of a recruitment pulse in the young nauplii, and mortality rates were determined. Since the VLT approach is best applied by averaging across several values (Aksnes \& Ohman 1996), we averaged across all stations and repeat sampling events to determine average mortality $( \pm 95 \%$ CI). Negative mortality estimates at individual time points are not uncommon when using the VLT approach (Aksnes \& Ohman 1996), and such values have not been removed here; indeed, removal is unadvisable as this would give a positive bias to the results. Mortality rates were not calculated from the abundances of stages in the $100 \mu \mathrm{m}$ net samples as this net does not quantitatively collect many of the naupliar stages (Fig. 3).

Mortality rates of subadult stages were estimated by iteration using the equation of Mullin \& Brooks (1970):

$$
\frac{\exp ^{\beta D_{i}}-1}{1-\exp ^{-\beta D_{i+1}}}=\frac{N_{i}}{N_{i+1}}
$$

where $\beta$ is mortality across a stage pair, $N$ is the abundance of the stage $\left(\mathrm{m}^{-3}\right)$, and $D$ is the stage duration (d). Stage durations were predicted from Nielsen et al. (2002) and Sabatini \& Kiørboe (1994) (Table 2) together with seawater temperatures averaged over the top $100 \mathrm{~m}$ of the water column.

For the CV-adult pair the equation from Aksnes \& Ohman (1996) is:

$$
\beta=\frac{\ln \left(\frac{N_{\mathrm{CV}}}{N_{\text {Adult }}}+1\right)}{D_{\mathrm{CV}}}
$$

Mortality rates were derived separately for CV-adult females and $\mathrm{CV}$-adult males assuming a sex ratio in CV of 1:1.

Development times in the field may be longer than those under high food abundance in the laboratory, on which our development times are based. In order to make an assessment of the impact of extended development times on mortality we therefore also derived mortality rates (for the $50 \mu \mathrm{m}$ mesh net results) assuming that the duration of the feeding stages (NI-CV) were twice those predicted from the Bêlehràdek functions in Table 1. We chose values twice as high as laboratory values, as this should encompass strong food limitation; such an extension has been observed in other copepods under conditions of strong food limitation (e.g. Calanus finmarchicus, Campbell et al. 2001). Unfortunately, we do not have data specific to Oithona relating development to food concentration.

As mortality is expressed in units of per day, and yet different stages can have different durations, it is useful to consider the proportion that survives a particular stage or stage pair. To determine $P$, the proportion surviving through a stage pair $i$ and $i+1$, we use the equation:

$$
P=[\exp (-\beta)]^{D_{i}+D_{i+1}}
$$

Mortality rates obtained in the present study were compared with those in early spring in the North Sea (Eiane \& Ohman 2004) and post-spring bloom in Disko Bay, western Greenland (Thor et al. 2008). We made these comparisons in order to examine if there are any discernible patterns in Oithona mortality, e.g. if some stages are consistently more vulnerable, and whether this is observed across different locations. This also allows a comparison of the absolute rates between areas.

\section{RESULTS}

The mean number $( \pm \mathrm{SD})$ of $O$. similis counted per sample (both aliquots combined) was $293 \pm 164$ copepodites, $319 \pm 253$ naupliar stages, and $53 \pm 40$ egg sacs. Both Oithona similis and $O$. frigida were present in the samples. Descriptions of the adults of both species of Oithona are given by Bradford-Grieve et al. (1999) and are easily separated. Younger copepodites of $O$. frigida were distinguished from those of $O$. similis by their distinct morphology, i.e. their larger size, large maxillipeds, rostral prominence and their more hyaline

Fig. 2. Oithona similis. Mean abundance of $O$. similis stages when sampled with $50 \mu \mathrm{m}$ nets, $100 \mu \mathrm{m}$ nets and water bottles at each of the 8 sampling stations. Abundance values have been integrated over the top $400 \mathrm{~m}$ of the water column. Error bars $( \pm \mathrm{SD})$ are determined from repeat sampling of the water column 


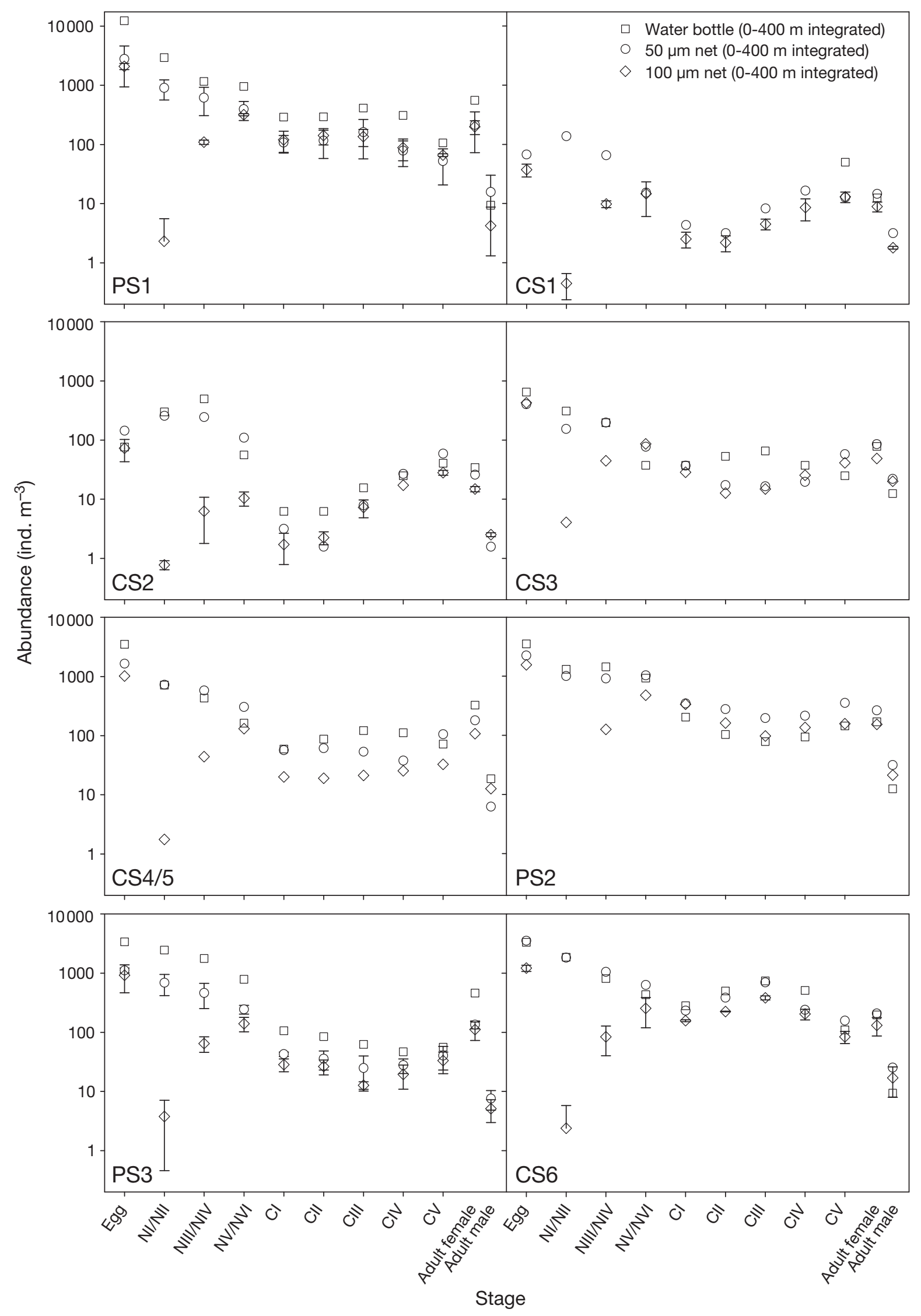


appearance. Examination of Oithona spp. nauplii indicated 2 distinct types present in samples, differing in size and some aspects of their morphology. O. similis nauplii were consistent with the description of Sazhina (1985) and were overwhelmingly more abundant than the other species, which was larger for a given stage and had noticeable differences in the spination of the furca. We attributed the latter type to $O$. frigida and overall they never exceeded $4 \%$ of the total of Oithona nauplii. Egg sacs attributable to $O$. frigida were also extremely rare in our samples, with $<1 \%$ of females carrying them. $O$. frigida copepodites, although present at every station sampled, were outnumbered by $O$. similis by 2 to 26 times for the $100 \mu \mathrm{m}$ net and 2 to 120 times for the $50 \mu \mathrm{m}$ net. The lowest ratios occurred at the ice-influenced Stns CS1, CS2 and CS3 for both nets and the highest occurred at Stn PS1.

\section{Stage abundance}

The abundance of any stage (or stage pair) varied widely from station to station by up to 2 orders of magnitude across the study region (Fig. 2): it was highest in the more northerly stations (Stns PS1, CS4/5, PS2, PS3 and CS6), and lowest in the 3 most southerly stations, located near, or within, the retreating seasonal ice edge (Stns CS1, CS2 and CS3). The fact that these 3 southerly stations were in an area where the physical and, possibly, food environment had significantly altered in recent weeks as the ice edge retreated may explain why the populations here had a non-steadystate composition, with a larger number of both late stage copepodites than early copepodite stages, and nauplii than eggs.

There were striking differences in the abundance estimates between the 3 sampling methods, particularly for the early and, therefore, smaller stages (Fig. 2). Consequently, the sampling methods were examined more closely by comparing the ratio of abundance of both the 50 and $100 \mu \mathrm{m}$ mesh nets with the water bottle samples (Fig. 3). For the earliest nauplii stages, the $100 \mu \mathrm{m}$ mesh nets gave much lower abundance estimates than the water bottles (Fig. 3b): up to 320 times lower for the NI-NII stages. This undersampling by the $100 \mu \mathrm{m}$ net is unsurprising as NI-NII have a mean $( \pm \mathrm{SD})$ body width of $62 \pm 9.6 \mu \mathrm{m}$, i.e. less than the mesh width. Width and length increase with stage, and the ratio of the abundance in the coarse mesh net to that in the water bottle increases steeply towards unity as size of stage increased beyond the mesh width of the net. The stage pair NV-NVI has a mean width of

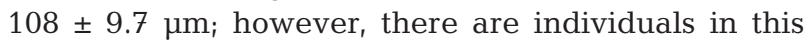
stage pair with a width $<100 \mu \mathrm{m}$, and not surprisingly it was also undersampled by the $100 \mu \mathrm{m}$ mesh net. For

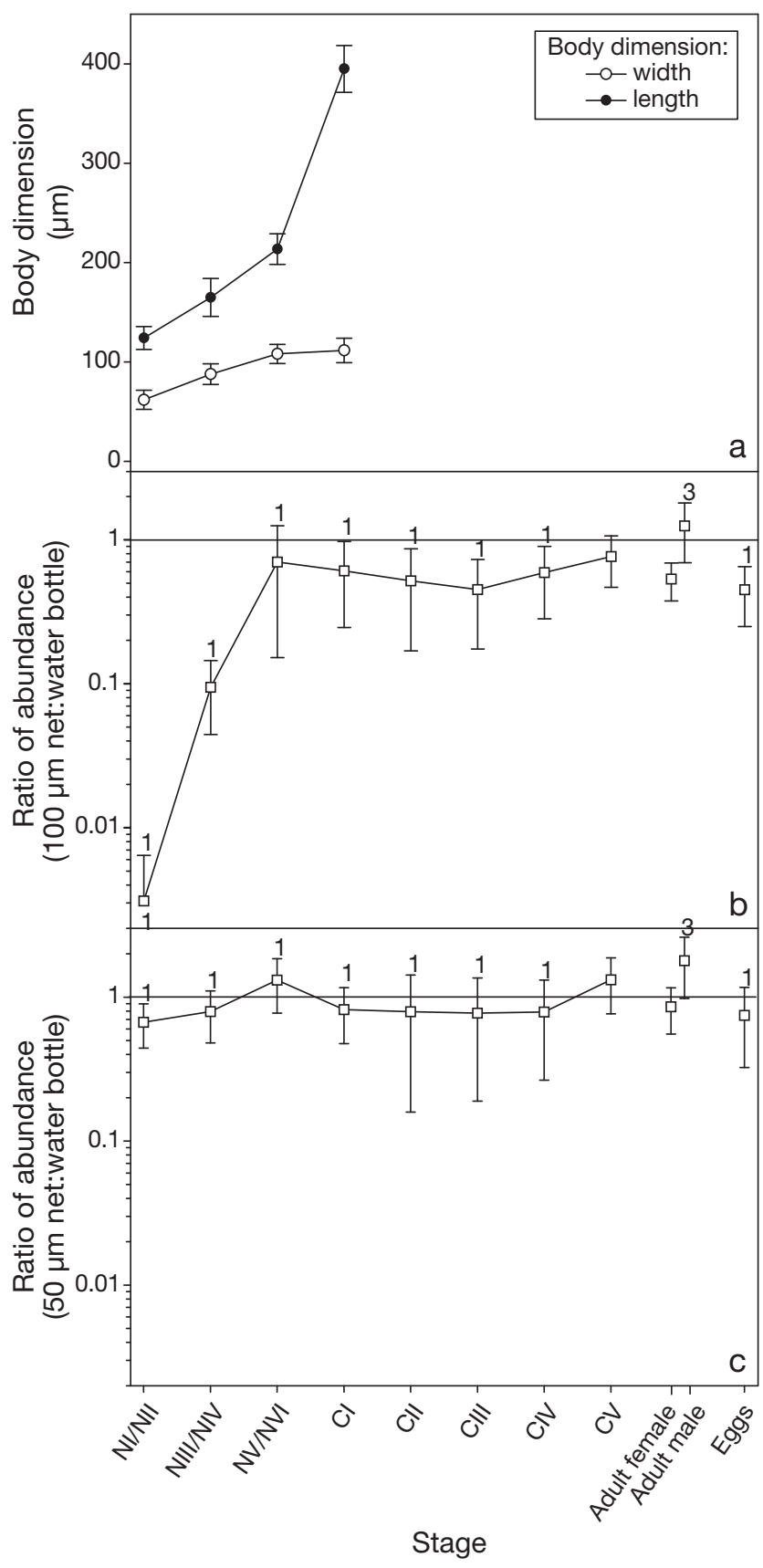

Fig. 3. Oithona similis. (a) Total lengths and widths of $O$. similis stages (error bars $\pm \mathrm{SD}$ ). (b) Mean ratio of the abundance of animals derived from $100 \mu \mathrm{m}$ mesh net and water bottle collections across the study sites (error bars $\pm 95 \%$ CI). (c) Mean ratio of the abundance of animals derived from $50 \mu \mathrm{m}$ mesh net and water bottle collections across the study sites (error bars $\pm 95 \%$ CI). In panels (b) and (c), the horizontal line indicates a ratio of $1: 1$, i.e. where the 2 sampling methods give equal abundance. When a collection method found no animals of a given stage a ratio could not be obtained for a station. The number of occasions a stage was not present is indicated; numbers above the mean are the number of occasions the water bottle at a station returned a zero value, numbers below the mean are where the relevant net found no animals. Note change in scale 
individuals of stage CI and greater the ratio of abundance between the $100 \mu \mathrm{m}$ net and water bottle stabilized around 0.5 to 0.8 , and there was no suggestion that size played a role in the different capturing abilities of the 2 sampling methods as the abundance appeared to be approximately constant even with increasing size beyond CI. The relative abundance of stages between the $50 \mu \mathrm{m}$ net and the water bottle samples gave ratios which, in every case except NI-NII, were not significantly different from 1 (i.e. the $95 \%$ confidence limits encompass the ratio of 1 ).

The mean number of eggs per sac was relatively invariant between stations, with station means ranging from 10.8 to 13.4 , giving an overall mean of 12.2 eggs $\mathrm{sac}^{-1}$. EPR derived from the $50 \mu \mathrm{m}$ mesh net hauls ranged between 0.12 (Stn CS1) and 1.86 eggs female $^{-1}$ $\mathrm{d}^{-1}$ (CS6), with rates being generally lower in the 3 stations closest to the ice edge (Stns CS1, CS2 and CS3) at $<0.15$ eggs female ${ }^{-1} \mathrm{~d}^{-1}$.

\section{Vertical distribution of stages}

We were able to discern how stage abundance changed with depth from the water bottle samples (Fig. 4). The vertical distribution of stages was very variable and differed from one stage to the next. Although the nets sampled from $400 \mathrm{~m}$ to the surface, water bottle samples indicated that at most stations, irrespective of latitude, the population was largely confined to the upper $100 \mathrm{~m}$ of the water column. Some stages were highly abundant at one depth and yet completely absent in bottle collections made at adjacent depths. Often adult females were found at depths at which no egg sacs were found; for example, on several occasions adult females were found at $300 \mathrm{~m}$ but no egg sacs were present. Egg sacs were generally most abundant in the top $100 \mathrm{~m}$. EPR per female therefore changed radically throughout the water column.

\section{Mortality}

In those stations away from the ice edge, stage duration-corrected abundance values declined across consecutive developmental stages on almost all occasions (Fig. 5), supporting our assumption that a VLT approach was suitable. However, there were a few instances in the $50 \mu \mathrm{m}$ net and water bottle samples in which numbers increased from stage to stage. Such increases never exceeded a factor of 2.5 , and almost exclusively occurred from stages CIII to CV. They could be indicative of inaccurate prediction of stage duration (overestimating the duration of the younger stage or underestimating that of the older stage) or sampling error. Mortality values across these late stages may be somewhat underestimated as a result. Stage-specific mortality rates averaged across all stations (excluding Stns CS1, CS2 and CS3) are presented in Fig. 6. Egg-NI-NII average mortality rates were $\sim 0.04 \mathrm{~d}^{-1}$, falling to $<0.03 \mathrm{~d}^{-1}$ in older stages, and then rising for $\mathrm{CV}$-adult males. $\mathrm{CV}$-adult males showed the highest mortality rates of any stages, at $0.110 \mathrm{~d}^{-1}$ calculated from the $50 \mu \mathrm{m}$ mesh net samples (assuming stage duration is identical to the laboratory rate). The corresponding $\mathrm{CV}$-adult female rate was $0.018 \mathrm{~d}^{-1}$. Thus, CV-adult male mortality rates were $\sim 6$ times those of the CV-adult females. As there are no sexspecific data on stage duration of $\mathrm{CV}$ males or females we have assumed these are equal in our estimate of mortality. However, the stage duration of CV males is typically somewhat less than females in copepods (Uye et al. 1983, Jerling \& Wooldridge 1991, Devreker et al. 2007), and allowing for such a difference would tend to increase the mortality of $\mathrm{CV}$-adult males relative to CV-adult females.

When we assume stage durations are twice those estimated from the laboratory, the estimated mortality rates decrease, except across stages egg-NI/NII and NV/NVI-CI. Generally, differences are small in absolute terms, except across stages NI/NII-NIII/NIV and $\mathrm{CV}$-adult males for which the values are much lower (see Fig. 6).

A comparison of mortality rates from the present study and those in early spring in the North Sea (Eiane \& Ohman 2004) and post-spring bloom in Disko Bay, western Greenland (Thor et al. 2008) yielded variable results (Fig. 7). Mortality rates for NI and NII were $\sim 0.07$ and $0.03 \mathrm{~d}^{-1}$, respectively, in Eiane \& Ohman (2004), and our value for egg-NI/NII falls between these at $0.04 \mathrm{~d}^{-1}$. Thor et al.'s (2008) estimated mortality across all nauplii pooled (nauplii-CI) is $0.008 \mathrm{~d}^{-1}$, which is close to Eiane \& Ohman's (2004) values from NIII to CI (at 0.0 to $0.006 \mathrm{~d}^{-1}$ ), but somewhat lower than in the present study (at 0.02 to $0.04 \mathrm{~d}^{-1}$ ). Eiane \& Ohman (2004) found elevated levels of mortality in NI and NII, and we also found higher mortality levels in the earliest nauplii. Eiane \& Ohman (2004) found that after the NII stage mortality rates were almost negligible $\left(<0.003 \mathrm{~d}^{-1}\right)$. This is in contrast to those found by Thor et al. (2008) and in the present study, in which rates are substantial after NII, often greatly exceeding $0.01 \mathrm{~d}^{-1}$. However, our estimate of $\mathrm{CV}$-adult female mortality of $0.018 \pm 0.011 \mathrm{~d}^{-1}( \pm 95 \% \mathrm{CI}$ ) (from the $50 \mu \mathrm{m}$ nets) is 6 times greater than Eiane \& Ohman's (2004) value for adult females alone of $0.003 \pm 0.031 \mathrm{~d}^{-1}$. Thor et al. (2008) do not consider mortality of the sexes separately, and found a value across CV-adults of $0.014 \mathrm{~d}^{-1}$. 

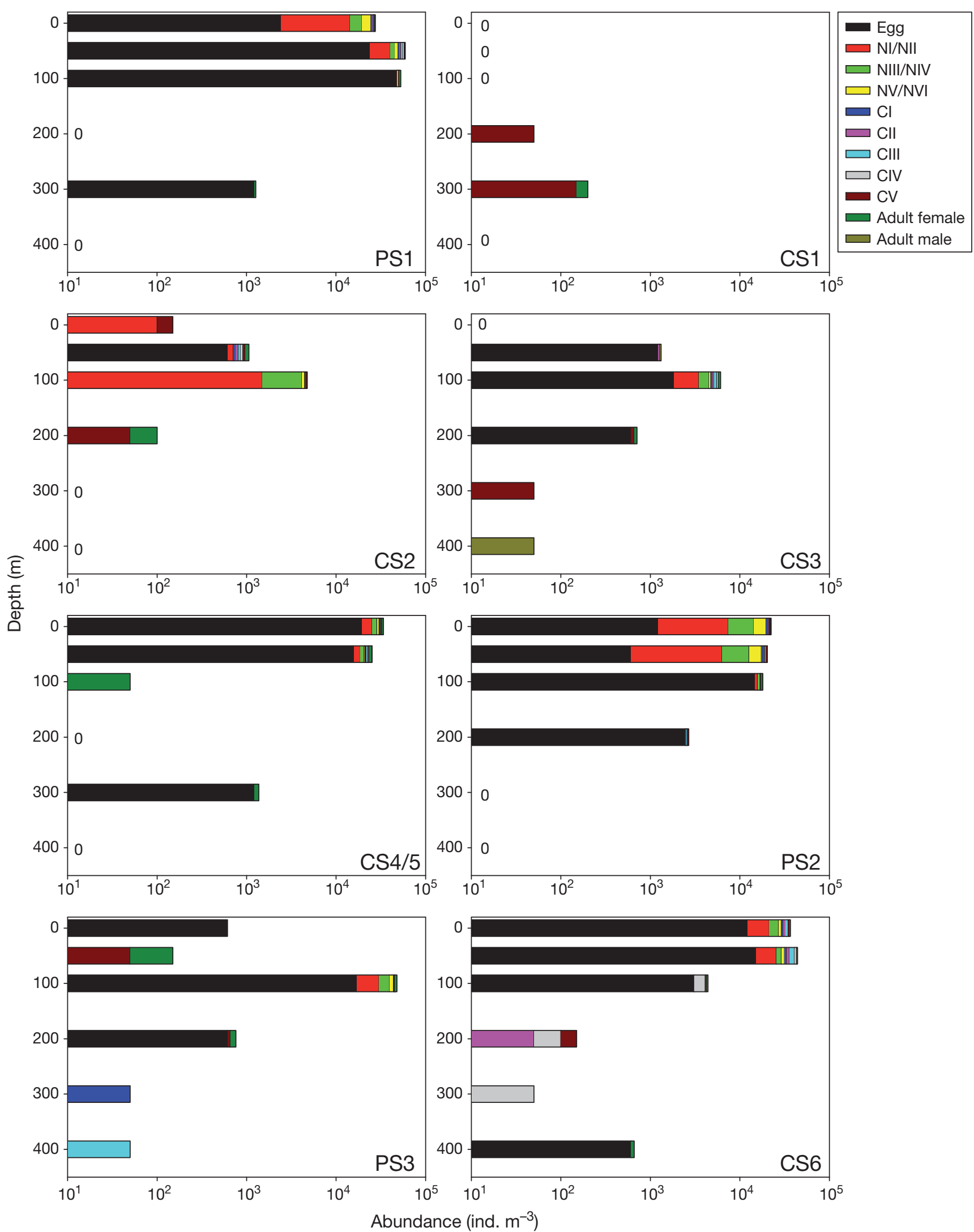

Fig. 4. Oithona similis. Vertical distribution of life-history stages determined from water bottles across the 8 sampling stations 


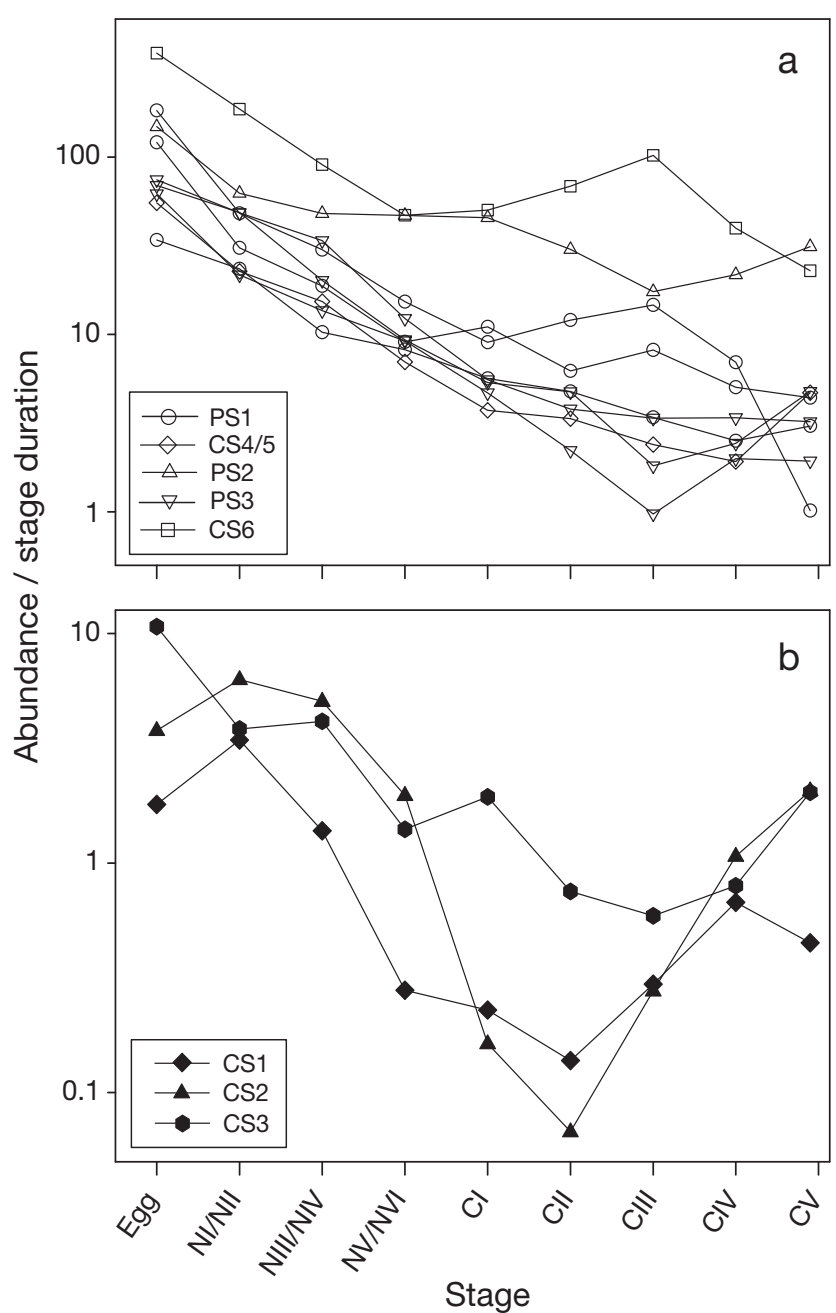

Fig. 5. Oithona similis. Stage abundance divided by duration for the $50 \mu \mathrm{m}$ net collected samples integrated over $0-400 \mathrm{~m}$. (a) Stations located away from the ice edge for which mortality rates were derived. (b) Those stations near the edge of the seasonal ice edge (Stns CS1, CS2 and CS3) which were not included in mortality estimates as they violate the assumptions of the vertical life-table approach. Note change in scale

\section{DISCUSSION}

\section{Stage abundance}

In the present study we obtained stage abundance data on Oithona similis across a transect in the Scotia Sea during austral spring (October to December) 2006, using 2 net types (50 and $100 \mu \mathrm{m}$ mesh) and water bottle samples. We found evidence that the population had a recruitment pulse (cohort) at those stations nearest the retreating ice edge (Stns CS1, CS2 and CS3), with greater numbers of late copepodite stages than younger stages, and, at 2 of these stations (Stns CS1 and CS2), greater numbers of early nauplii than eggs. These 3 stations were not used to quantify mortality, as

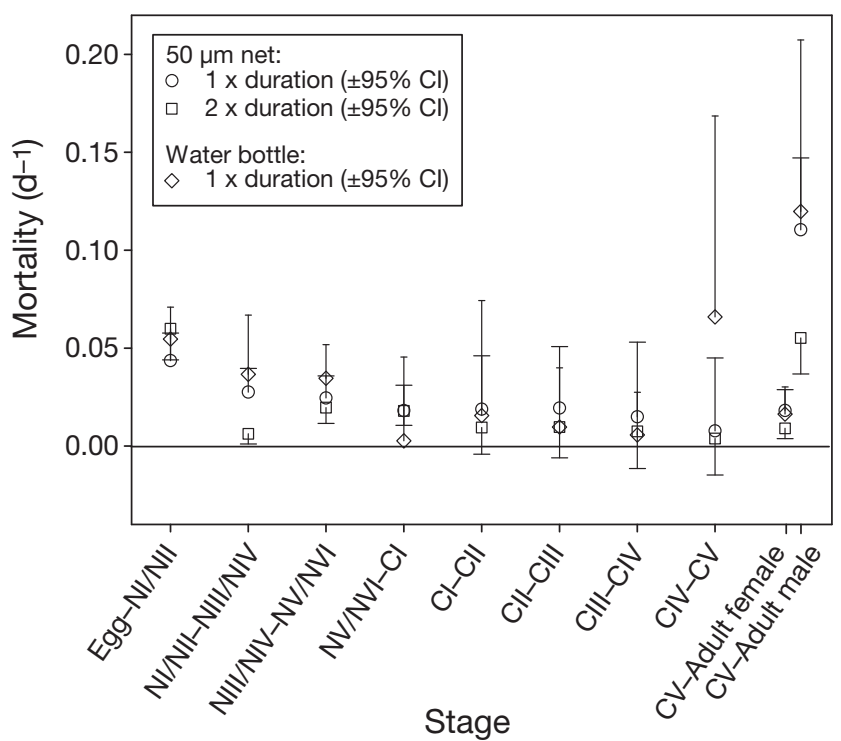

Fig. 6. Oithona similis. Mortality rates across stages determined from abundance values from both $50 \mu \mathrm{m}$ net and water bottle collections. Values are arithmetic means derived using data from all stations (except Stn CS1, CS2 and CS3 for nets and bottles)

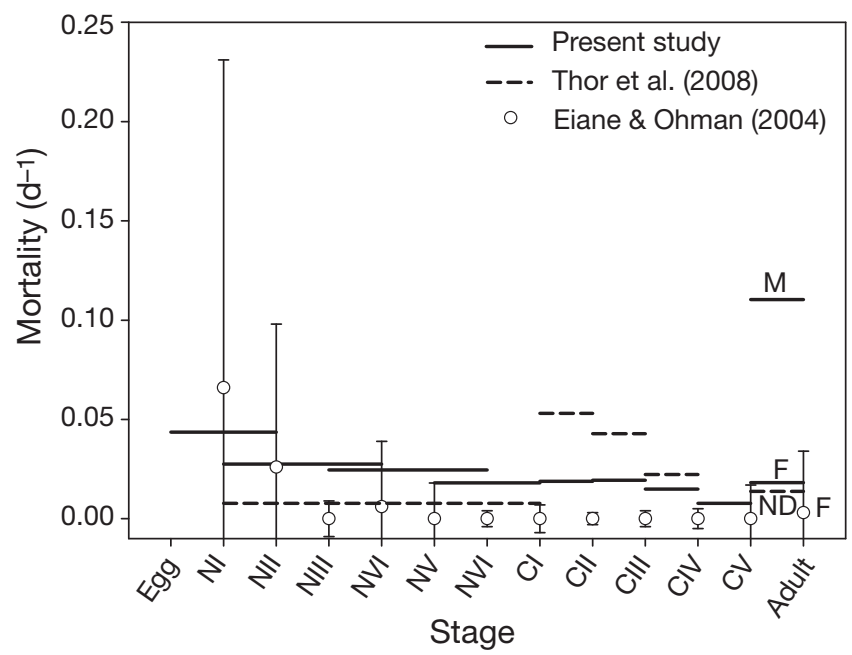

Fig. 7. Oithona similis. Comparison of mortality rates across the developmental stages of $O$. similis in the Scotia Sea in the present study (using $50 \mu \mathrm{m}$ mesh nets and assuming laboratory duration of stages) with those from the Fladen Ground, North Sea (Eiane \& Ohman 2004) and Disko Bay, western Greenland (Thor et al. 2008). For adult and CV-adult mortality rates sexes are denoted as M (male), F (female) and ND (not determined)

the population violated VLT assumptions. We suggest the great abundance of young nauplii stages resulted from recent pulses of reproduction and/or alternating high and low survival of young stages in the ice edge region. This may reflect recent changes in the physical environment as the ice edge retreated, with subse- 
quent changes in food availability or the predation regime. It is not uncommon for retreating ice edge environments to have associated algal blooms as light increases and the water column is stratified by the input of fresh meltwater.

The fine mesh net $(50 \mu \mathrm{m})$ gave slightly lower stage abundance values on average than those from the water bottle (Fig. 3c). However, as indicated from the $95 \% \mathrm{CI}$, the ratio of $50 \mu \mathrm{m}$ mesh net abundance to water bottle abundance did not significantly differ from 1 (except in one case). The smallest of the 30 NI/NII we measured were $50 \mu \mathrm{m}$ wide and the average was $62 \mu \mathrm{m}$; individuals of these sizes are captured by a $50 \mu \mathrm{m}$ mesh net with an efficiency of 50 and 90\% respectively (Nichols \& Thompson 1991). Losses of NI/NII are likely to be small, but would lead to some overestimation of mortality across egg-NI/NII stages and underestimation across NI/NII-NIII/NIV stages. The naupliar stages were greatly undersampled by the $100 \mu \mathrm{m}$ net in comparison to both water bottles and the $50 \mu \mathrm{m}$ net, and by an increasingly large amount at earlier, smaller stages. Stages NI/NII were the most under-represented, although undersampling is clear in all the other naupliar stages, and possibly for the first copepodite stage in the $100 \mu \mathrm{m}$ net.

There were several occasions when stages were missing from the water bottle samples at a station, but present in the fine mesh net collections at the same station. This is unsurprising, as water bottles can only practically be used to make collections at a limited number of depth horizons, and only sampled 201 per depth horizon in the present study. It would be advisable to increase this volume where abundances are known or suspected to be too low to be adequately sampled by small volume water bottle collections.

Abundance estimates from the $100 \mu \mathrm{m}$ mesh nets were never as great as those from the water bottles or $50 \mu \mathrm{m}$ nets (the fine mesh gives abundance values which are 1.4 to 1.7 times those in the coarse net in stage CI and older). Although it has a larger mesh size, this net design (WP2 design) has a lower mesh to net mouth area ratio (at 12.7) than does the fine mesh net (at 52). The open area ratio (OAR) of the $100 \mu \mathrm{m}$ mesh itself is $40 \%$, whilst for the $50 \mu \mathrm{m}$ mesh it is $32 \%$, and therefore the ratio of total net mesh open area to net mouth area is 5.1 for the $100 \mu \mathrm{m}$ net, but 16.6 for the $50 \mu \mathrm{m}$ net. It is clear that the $100 \mu \mathrm{m}$ mesh net does not filter a volume equal to tow distance multiplied by mouth area, possibly due to back pressure in the net during towing, which leads to an underestimation of the individual density.

Station means of the number of eggs per sac in Oithona similis ranged from 10.8 to 13.4 , with an overall mean of 12.2 in the spring. Ward \& Hirst (2007) found a higher overall mean of 15.8 eggs sac ${ }^{-1}$ across the Scotia Sea in the summer, these differences suggesting a seasonal effect, probably driven by food, temperature, or both. The mean number of eggs per sac found in the present study is relatively invariant between stations, a feature also noted by Ward \& Hirst (2007). Nielsen \& Sabatini (1996) found that site averages in a study of Oithona spp. (presumably dominated by $O$. similis) in the North Sea ranged from 10 to 15.2 eggs $\mathrm{sac}^{-1}$, and Castellani et al. (2007) found $\sim 6$ to 16 eggs $\mathrm{sac}^{-1}$ in $O$. similis in the Irminger Sea off Greenland.

EPR derived from the $50 \mu \mathrm{m}$ mesh net hauls ranged between 0.12 and 1.86 eggs female $\mathrm{e}^{-1} \mathrm{~d}^{-1}$, with rates being $<0.15$ eggs female ${ }^{-1} \mathrm{~d}^{-1}$ at the 3 most southerly stations near the ice edge (Stns CS1, CS2 and CS3), while at the relatively warmer more northerly stations they were always $>0.31$ eggs female ${ }^{-1} \mathrm{~d}^{-1}$. The pattern of greater rates in warmer waters fits with general expectations, and the rates are close to previously published values (see Castellani et al. 2007, Ward \& Hirst 2007, their Figs. 6a \& 7).

The $100 \mu \mathrm{m}$ mesh net used here was the same as that used by Ward \& Hirst (2007) to determine EPR across the Scotia Sea. They argued that the egg sacs were large enough to ensure that even if these are dropped by the female, they will not be lost from the net. Results from the present study confirm this assertion, and their EPR estimates per capita should not be biased. However, the situation is more complex: the $100 \mu \mathrm{m}$ net gives abundance values that are $\sim 0.5$ times those from the water bottles for both eggs and adult females (Fig. $4 \mathrm{~b})$, so total water column EPR $\left(\mathrm{m}^{-3}\right)$, i.e. when not expressed on a per female basis, will have been underestimated by around $1 / 2$ in Ward \& Hirst (2007).

\section{Mortality rates}

Mortality rates derived from the $50 \mu \mathrm{m}$ net abundance values, assuming that durations of feeding stages are twice those in the laboratory, were highest for eggs-NI/NII at $0.060 \mathrm{~d}^{-1}$ and for CV-adult males at $0.055 \mathrm{~d}^{-1}$ (Fig. 6). These values are 0.044 and $0.110 \mathrm{~d}^{-1}$, respectively, assuming laboratory stage durations. Mortality rates calculated from the water bottles are in very good agreement with rates from the $50 \mu \mathrm{m}$ net, with the exception of CIV-CV, where the values from the water bottle abundances are larger. This is driven by a stronger decline in abundance across this stage pair in the water bottle samples at Stns CS4/5 and CS6 than the fine mesh net samples. A disadvantage of the water bottle is that at Stn CS2 it failed to sample most stages, and at 3 other stations (Stns CS1, CS2 and PS3) it missed adult males, although nets collected these. The numbers of times stages were missing are given in 
Fig. 3. It is for this reason that we place most emphasis on mortality rates from the $50 \mu \mathrm{m}$ mesh nets, and consider these better for determining mortality.

Our results continue to highlight the relatively low mortality rates and high survival of carried eggs, which is in stark contrast to the pattern of broadcast eggs. On average, the proportion of Oithona similis surviving $(P)$ the egg-NI/NII stages in the present study was $24 \%$ (range $=6$ to $49 \%$ ). By contrast, in broadcast spawning species, survival is usually much lower; for example, often $<1 \%$ of Calanus helgolandicus survived the egg-NI stage in a seasonal study in the English Channel (Hirst et al. 2007).

Different copepod species show marked differences in their degree of development upon hatching, and this can include feeding ability. In Oithona similis, feeding commences at stage NI, and the elevated estimates of mortality rates in the early, relative to the late naupliar stages and the copepodites, likely reflect the poor performance of the youngest nauplii in finding sufficient food or in escaping predation. Although mortality rates were relatively consistent for early naupliar stages (egg-NII), differences between the present study and those of Eiane \& Ohman (2004) and Thor et al. (2008) became more pronounced at later stages, specifically the CV-adult stage. These differences may reflect variability in mortality between locations and period of the year; this may be a result of different predator types with different feeding rates, or a reflection of the quantity or quality of available food.

\section{Sexual differences in mortality}

There was an increase in CV-adult mortality relative to younger copepodite stages, and this was especially marked for the CV-adult males, whose mortality was $\sim 6$ to 7 times those of the CV-adult females. However, this gives a somewhat biased view, and may underestimate the true degree to which adult male mortality exceeds that of females, because the VLT method allows for differences in mortality rates of males and females in the CV stage. If, instead, sex-specific differences in mortality commence upon entry to adulthood, then the ratio of adult male to female mortality can be estimated from the ratio of male to female adult abundance. In this case, adult males would have an estimated mortality rate $\sim 12$ times those of females (i.e. the adult male to female abundance ratio is 0.08). A skew in sex ratio towards females is commonly observed in copepods, and by implication greater mortality rates in adult males are apparent (e.g. see Ohman \& Wood 1996, Ohman et al. 2002, Hirst et al. 2007).

A very strong skew towards females being numerically dominant has previously been noted in Oithona similis. Highly skewed sex ratios for adult $O$. similis of 0.18 were found in Loch Striven, Scotland (Marshall 1949), and off Plymouth, English Channel (Digby 1950), and a ratio of 0.06 was found in Scoresby Sound, Greenland (Digby 1954). Oithona is one of the most sex-skewed genera of epipelagic copepods (Hirst \& Kiørboe 2002, Kiørboe 2006), which may be indicative of the mate finding behaviour of the male being particularly perilous in comparison to the behaviour (which includes ambush feeding) of the females. Mate searching likely increases the rate at which they are preyed upon. The males' movements may increase encounter rates with predators, whilst also making them more visible and hydromechanically detectable to predators. In a study of $O$. davisae, Uchima \& Hirano (1988) found, for wild caught adults when starved or fed high concentrations of food in the laboratory (free from predators), that females lived 1.3 and 1.8 times longer than the males, respectively. This suggests that physiological longevity may not be the primary cause of the strong sex ratio skew in adult Oithona, but rather predation may be most important.

\section{CONCLUSIONS}

In the present study we derived mortality rates for egg to adult stage of Oithona similis in the Scotia Sea during the austral spring. Although zooplankton mortality research has made great strides over the last $20 \mathrm{yr}$, it continues to lag behind the understanding and prediction ability of growth and EPR, for which 10 s to 100 s of studies have attempted to obtain empirical relationships to body size, temperature and food. However, mortality rates are important to understanding seasonal and spatial changes in the abundance of these organisms. Other than the framework of Hirst \& Kiørboe (2002), we have little ability to predict mortality rates of copepods from more easily measurable parameters, whilst their model only addresses averages across seasons and species. Clearly, close examination of the seasonal rates and controls of mortality in marine copepods is needed, and polar waters have been especially understudied in this respect.

Acknowledgements. This work forms part of the Discovery 2010 (Flexicon) programme at BAS. We thank A. Fleming for providing the sea-ice data illustrated in Fig. 1. Ice edge data derived from DMSP SSM/I Monthly Polar Gridded Sea Ice Concentrations provided by the US National Snow and Ice Data Centre (http://nsidc.org/index.html). Thanks to D. Bone who designed the nets and for helpful discussion regarding their sampling efficiency, and to M. Sabatini for supplying data on Oithona similis development times. 


\section{LITERATURE CITED}

Aksnes DL, Ohman MD (1996) A vertical life table approach to zooplankton mortality estimation. Limnol Oceanogr 41: 1461-1469

Aksnes DL, Miller CB, Ohman MD, Wood SN (1997) Estimation techniques used in studies of copepod population dynamics: a review of underlying assumptions. Sarsia 82:279-296

Bradford-Grieve JM, Markhaseva EL, Rocha CEF, Abiahy B (1999) Copepoda. In: Boltovskoy D (ed) South Atlantic zooplankton. Backhuys Publishers, Leiden, p 869-1098

Bunker AJ, Hirst AG (2004) Fecundity of marine planktonic copepods: global rates and patterns in relation to chlorophyll $a$, temperature, and body weight. Mar Ecol Prog Ser 279:161-181

Campbell RG, Wagner MM, Teegarden GJ, Boudreau CA, Durbin EG (2001) Growth and development of the copepod Calanus finmarchicus reared in the laboratory. Mar Ecol Prog Ser 221:161-183

Castellani C, Irigoien X, Harris RP, Holliday NP (2007) Regional and temporal variation of Oithona spp. biomass, stage structure and productivity in the Irminger Sea, North Atlantic. J Plankton Res 29:1051-1070

Checkley DM (1980) Food limitation of egg production by a marine, planktonic copepod in the sea off southern California. Limnol Oceanogr 25:991-998

Devreker D, Souissi S, Forget-Leray J, Leboulenger F (2007) Effects of salinity and temperature on the post-embryonic development of Eurytemora affinis (Copepoda: Calanoida) from the Seine estuary: a laboratory study. J Plankton Res 29:i117-i133

Digby PSB (1950) The biology of the small planktonic copepods of Plymouth. J Mar Biol Assoc UK 29:393-438

Digby PSB (1954) The biology of the marine planktonic copepods of Scoresby Sound, East Greenland. J Anim Ecol 23: 298-338

Edmondson WT, Comita GW, Anderson GC (1962) Reproductive rate of copepods in nature and its relation to phytoplankton population. Ecology 43:625-634

Eiane K, Ohman MD (2004) Stage-specific mortality of Calanus finmarchicus, Pseudocalanus elongatus and Oithona similis on Fladen Ground, North Sea, during a spring bloom. Mar Ecol Prog Ser 268:183-193

Gallienne CP, Robins DB (2001) Is Oithona the most important copepod in the world's oceans? J Plankton Res 23: 1421-1432

Heath MR, Rasmussen J, Ahmed Y, Allen J and others (2008) Spatial demography of Calanus finmarchicus in the Irminger Sea. Prog Oceanogr 76:39-88

Hirst AG, Bunker AJ (2003) Growth of marine planktonic copepods: global rates and patterns in relation to chlorophyll $a$, temperature, and body weight. Limnol Oceanogr 48:1988-2010

Hirst AG, Kiørboe T (2002) Mortality of marine planktonic copepods: global rates and patterns. Mar Ecol Prog Ser 230:195-209

Hirst AG, Bonnet D, Harris RP (2007) Seasonal dynamics and mortality rates of Calanus helgolandicus over two years at a station in the English Channel. Mar Ecol Prog Ser 340: 189-205

Editorial responsibility: William Peterson,

Newport, Oregon, USA
Jerling HL, Wooldridge TH (1991) Population dynamcis and estimates of production for the calanoid copepod Pseudodiaptomus hessei in a warm temperate estuary. Estuar Coast Shelf Sci 33:121-135

Kiørboe T (1998) Population regulation and role of mesozooplankton in shaping marine pelagic food webs. Hydrobiologia 363:13-27

Kiørboe T (2006) Sex, sex-ratios, and the dynamics of pelagic copepod populations. Oecologia 148:40-50

Marshall S (1949) On the biology of the small copepods in Loch Striven. J Mar Biol Assoc UK 28:45-122

Matthews JBL, Hestad L, Bakke JLW (1978) Ecological studies in Korsfjorden, Western Norway. The generations and stocks of Calanus hyperboreus and C. finmarchicus in 1971-1974. Oceanol Acta 1:277-284

Mullin MM, Brooks ER (1970) Production of the planktonic copepod Calanus helgolandicus. Bull Scripps Inst Oceanogr 17:89-103

Nichols JH, Thompson AB (1991) Mesh selection of copepodite and nauplius stages of four calanoid copepod species. J Plankton Res 13:661-671

Nielsen TG, Sabatini M (1996) Role of cyclopoid copepods Oithona spp. in North Sea plankton communities. Mar Ecol Prog Ser 139:79-93

- Nielsen TG, Møller EF, Satapoomin S, Ringuette M, Hopcroft RR (2002) Egg hatching rate of the cyclopoid copepod Oithona similis in arctic and temperate waters. Mar Ecol Prog Ser 236:301-306

> Ohman MD, Hirche HJ (2001) Density-dependent mortality in an oceanic copepod population. Nature 412:638-641

Ohman MD, Wood SN (1996) Mortality estimation for planktonic copepods: Pseudocalanus newmani in a temperate fjord. Limnol Oceanogr 41:126-135

Ohman MD, Runge JA, Durbin EG, Field DB, Niehoff B (2002) On birth and death in the sea. Hydrobiologia 480: $55-68$

Sabatini M, Kiørboe T (1994) Egg production, growth and development of the cyclopoid copepod Oithona similis. J Plankton Res 16:1329-1351

Sazhina LI (1985) Nauplii of the major pelagic copepod species of the world's oceans. Naukova Dunka Press, Kiev (in Russian)

Shreeve RS (2002) Growth of two species of Southern Ocean copepod in relation to their environment. $\mathrm{PhD}$ thesis, The Open University, Milton Keynes

- Thor P, Nielsen TG, Tiselius P (2008) Mortality rates of epipelagic copepods in the post-spring bloom period in Disko Bay, western Greenland. Mar Ecol Prog Ser 359: 151-160

Uchima M, Hirano R (1988) Swimming behaviour of the marine copepod Oithona davisae: internal control and search for environment. Mar Biol 99:47-56

Uye S, Iwai Y, Kasahara S (1983) Growth and production of the inshore marine copepod Pseudodiaptomus marinus in the central part of the inland Sea of Japan. Mar Biol 73: 91-98

Ward P, Hirst AG (2007) Oithona similis in a high latitude ecosystem: abundance, distribution and temperature limitation of fecundity rates in a sac spawning copepod. Mar Biol 151:1099-1110

Submitted: January 8, 2008; Accepted: August 12, 2008

Proofs received from author(s): November 25, 2008 